\title{
6.
}

$615-092.23$

\section{Theophyllin-Äthylendiamin / 藥理學的研究}

\author{
（第 3 報） \\ 他 ノ Purin 誘導體卜ノ比較
}

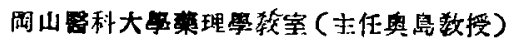

學士福 原晌文

[昭和 16 年 9 月 13 日受稿]

\section{緹言}

余八婁=Theophyllin誘留體ナルTheophyllinÄthylendiamin /落理學的研究》企圖シ，先ッ

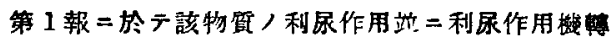

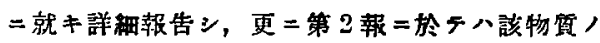

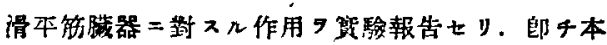
物斦八强烈ナ几利尿作用

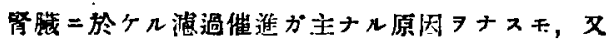

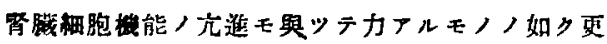
二觜外作用トンテ本物距八水血症９來ン利尿 クコトワ器明セり。

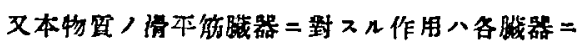

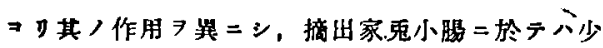

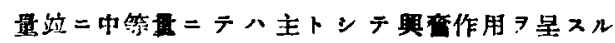

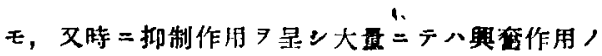

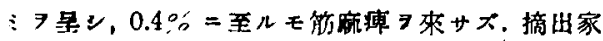
鬼子宫站二腾腅三角部二對シテハ少量 $コ$ オ量二

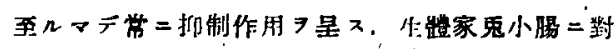

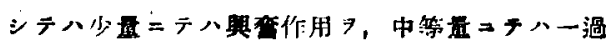

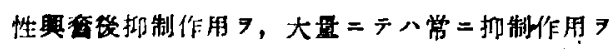

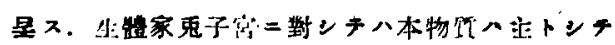

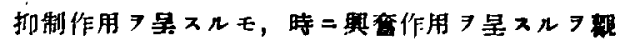

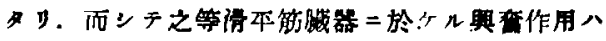

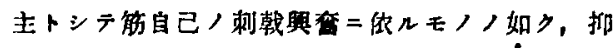

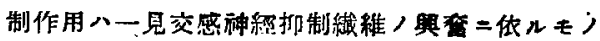

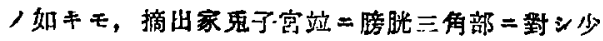

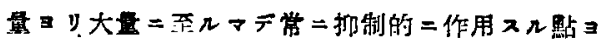

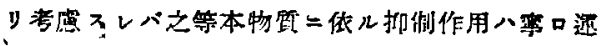

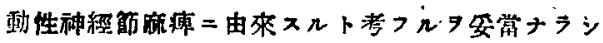

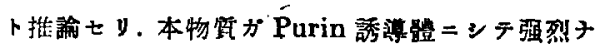

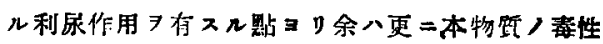

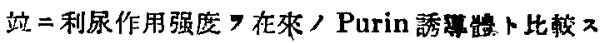

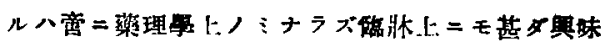

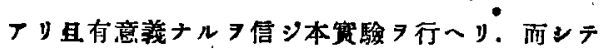

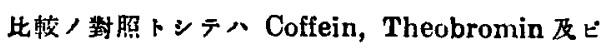

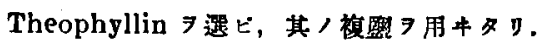

\section{－ 一般症狀站二致死量

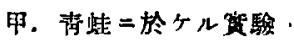

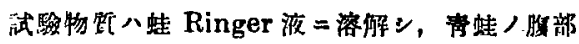

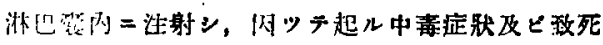
早檢索セリ.

A. 中毒症然

1) Theophyllin- Athylendiamin

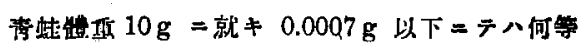

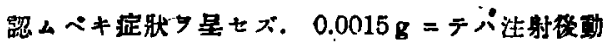

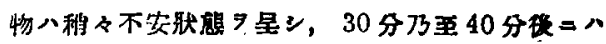

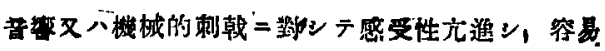




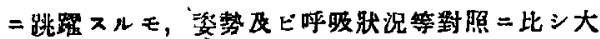
美ナク， 1-2 時間ニンテ金ク咴復ス。 $0.002 \mathrm{~g} 一$ $0.0025 \mathrm{~g}=$ テハ初×七部/症狀 7 呈シ, 呼吸稍々。 促迫シ, 注射後 10 一 20 分 $ン$ テ腹筋竝 $=$ 四肢，

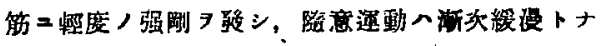

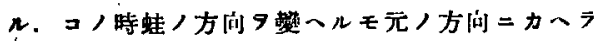

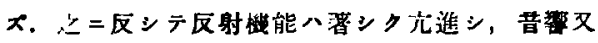
八接解其, 他

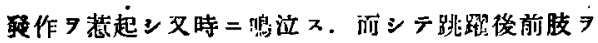

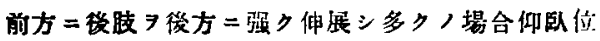
トナル，カカル酸作八数時間二シテ消散シ，動物 ハ稍々正常ノ體位

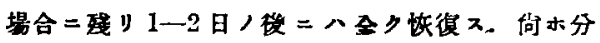
量 7 始加シテ $0.004 \mathrm{~g}=$ 至レバ其/症狀急々其ノ

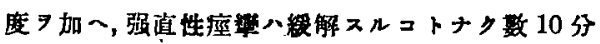

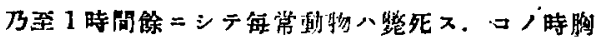

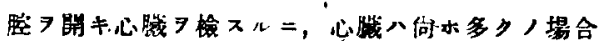
搏動又ル习祋メタリ。

2) Theocin (natrioacetat)

策驗二使用セれハBayer 製ノ「醋酸テォチン曹 蓬」ナリ.本物質へTheophyllin-Athylendiamin

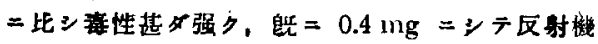
能ノ穴進 9 來スガ如キモ綮时ニシテ恢復ス. $1 \mathrm{mg}$

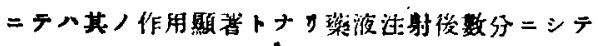

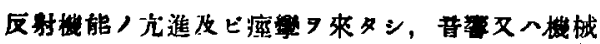

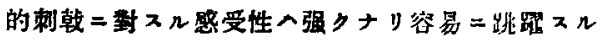

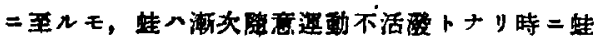

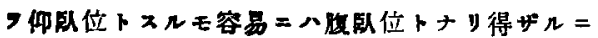

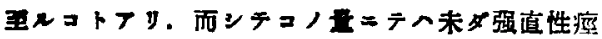

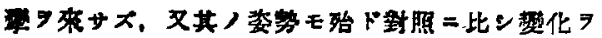

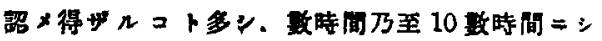

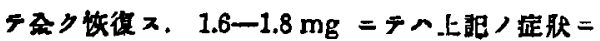

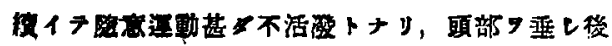

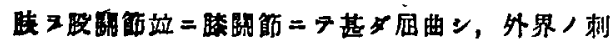

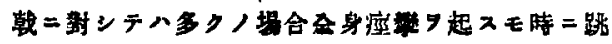

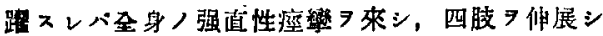
仰㭱位又八腹卧位トハ一定ゼズ.数 10 分後二八動 物八每常鹪死ス，阿シテコノ際二開胸スレパ心践 八佁水僅二接動スル 認メタリ。

3) 「筑息香酸ソニタ，カフェイン」及ビ Diuretin

阿孝八共二其，作用八前 2 物路卜作用相似，

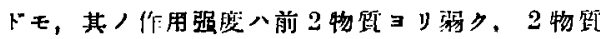

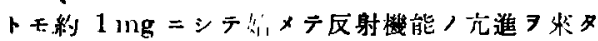
スモ数时間ニシテ恢嗖スルカ如シ．2-3 $\mathrm{mg}=$ テ

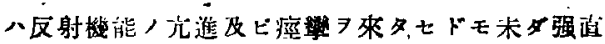

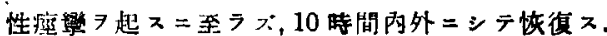

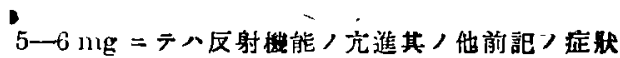

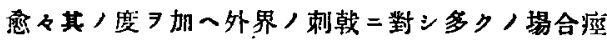

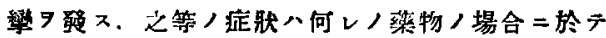

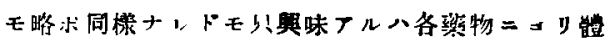

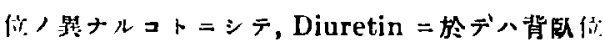

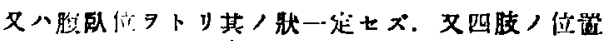
モ一腚ヒザレドモ，Caftein，場合二於テハ多ク

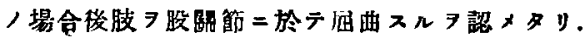

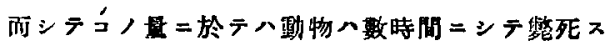
ルタ常トセリ。

B. 玟死量

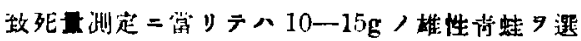

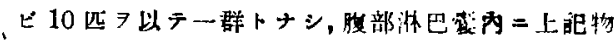

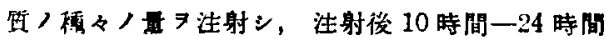

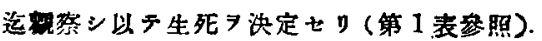

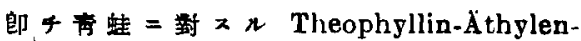
diamin, Theocin, Diuretin 改ビ「灾息香酟ソ一

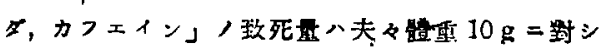
$3.5 \mathrm{mg}, 1.5 \mathrm{mg}, 5.5 \mathrm{mg}, 5.5 \mathrm{mg}+v . 之=$ 嘘》

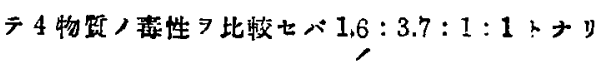

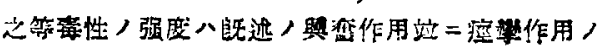
、强底ト略ボー一教スル 7 顆ル。 
第 1 表

\begin{tabular}{|c|c|c|c|c|}
\hline 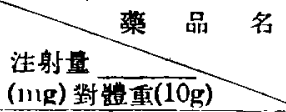 & $\begin{array}{l}\text { Theophyllin- } \\
\text { Athylendiamin }\end{array}$ & $\begin{array}{c}\text { Theocin } \\
\text { (natr. acetic.) }\end{array}$ & Diuretin & $\begin{array}{l}\text { Coffeino- } \\
\text { natr. benzoic. }\end{array}$ \\
\hline 0.7 & & $1 / 10$ & & \\
\hline 1.0 & & $1 / 10$ & & \\
\hline 1.2 & & $2 / 10$ & & \\
\hline 15 & & $5 / 10$ & & \\
\hline 1.8 & & $9 / 10$ & & \\
\hline 2.0 & $1 / 10$ & $10 / 10$ & & \\
\hline 2.5 & $2 / 10$ & & & \\
\hline 3.0 & $3 / 10$ & & & \\
\hline 3.5 & $5 / 10$ & & & \\
\hline 4.0 & $8 / 10$ & & $1 / 10$ & $1 / 10$ \\
\hline 1.5 & $10 / 10$ & & $2 / 10$ & $2 / 10$ \\
\hline 5.0 & & & $3 / 10$ & $4 / 10$ \\
\hline 5.5 & & & $5 / 10$ & $5 / 10$ \\
\hline 6.0 & & & $8 / 10$ & $9 / 10$ \\
\hline 7.0 & & & $10 / 10^{\circ}$ & $10 / 10$ \\
\hline
\end{tabular}

乙.「マウス」於ケル宽驗

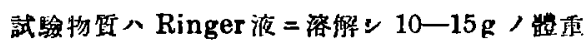

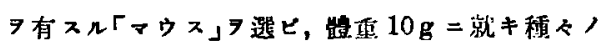
量 7 其，背部皮下 $=$ 注射 $ン$ 因ッテ起几中毒症肰 检已，且其/致死量 7 測定七 $y$.

\section{A. 中策症狀}

1) Theophyllin-Äthylendianin

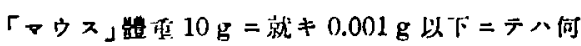

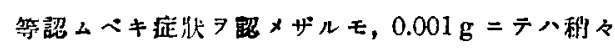

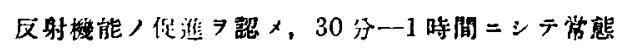

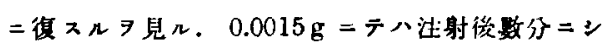
テ動物ハ稍々不安狀態 シ示ン反射機能ハ立進ン，

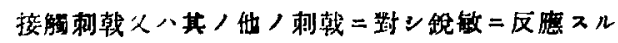

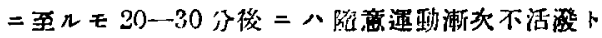
ナリ時二胜部 1 13時間エシテ常態二復ス。 $0.002-0.0025 \mathrm{~g}=$ テ

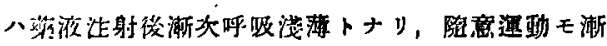

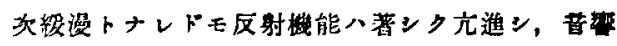

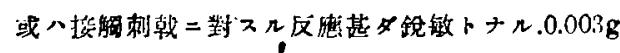

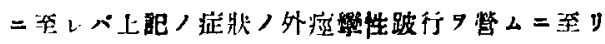

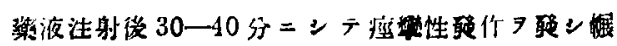

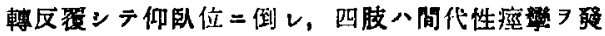

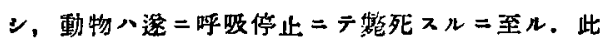
祭開胸ンテ心臟 スルカヌ八推張期二你止スルワ見ル。

2) Theocin, Diuretin, 「安息香醊ンーダ，カ フーイン」

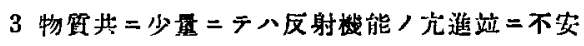

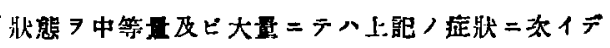

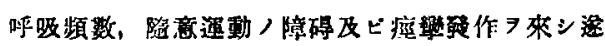
二呼吸麻溥 7 米ス八Theophyllin-Äthylendiamin

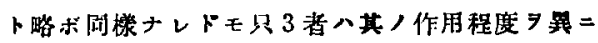
スルノ、。即手Theocin八0.00025 $\mathrm{g}=$ テ既=反

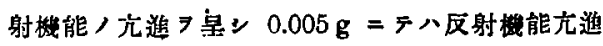
ノ外二呼吸澄薄トナリ，時二䧗部

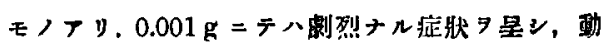
物八透二呼吸侉止 7 來 $\pi$. Diuretin $八 0.0008$ $0.001 \mathrm{~g}=\bar{\gamma}$ 㑤 $0.006 \mathrm{~g}=$ テ呼吸停止 $\ni$ 來ス。「安息香酸ンーダ, カ

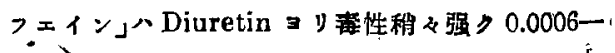
$0.0008 \mathrm{~g}=$ 荄度/中梅症狀 7 吴之, $0.003-0.004 \mathrm{~g}$ ニテ每常呼吸停止ニコり路死センム。 


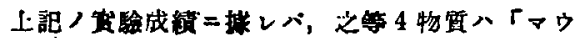
ス」ニ於テモ青蛙卜略ボ同栐ノ作用 7 旺

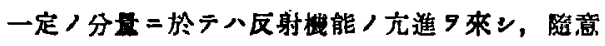

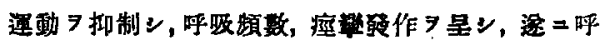
吸停止 ニテ死 7 招來ス，而ンテ心歲停止八常二呼 喓停止ノ後二來几
與一タル際ニハ多クノ場合放尿スルヌ詔メタリ。

\section{B. 政死量}

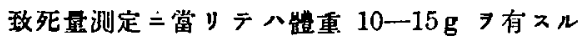
焳性ノ「マゥス」ヨ選ビ，5匹ョ以テ 1 群トナシ， 背部皮下 $=$ 各藥物ノ皬々，量 7 注射シ，注射後 24

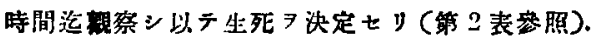

第 2 表

\begin{tabular}{|c|c|c|c|c|}
\hline $\begin{array}{l}\text { 注射量 } \\
(\mathrm{mg}) \text { 對萣重(10g) }\end{array}$ & $\begin{array}{l}\text { Theophyllin- } \\
\text { Athylendiamin }\end{array}$ & $\begin{array}{c}\text { Theocin } \\
\text { (natr. acetic.) }\end{array}$ & Diuretin & $\begin{array}{c}\text { Coffeino- } \\
\text { natr. benzoic. }\end{array}$ \\
\hline 0.7 & & . $2 / 5$ & & \\
\hline 1.0 & & $3 / 5$ & & \\
\hline 1.2 & $1 / 5$ & $3 / 5$ & & \\
\hline 1.5 & $1 / 5$ & $5 / 5$ & & \\
\hline 2.0 & $2 / 5$ & & & \\
\hline 2.5 & $\dot{3} / 5$ & & & \\
\hline 3.0 & $4 / 5$ & & & $1 / 5$ \\
\hline 3.5 & $5 / 5$ & & & $2 / 5$ \\
\hline 4.0 & & & & $4 / 5$ \\
\hline 4.5 & & & $2 / 5$ & $5 / 5$ \\
\hline 5.0 & & & $2 / 5$ & \\
\hline 6.0 & & & $3 / 5$ & . \\
\hline 6.5 & & & $3 / 5$ & \\
\hline 7.0 & & & $5 / 5$ & \\
\hline
\end{tabular}

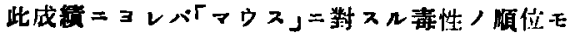

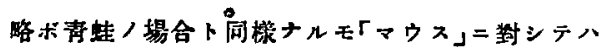
「安息香破ソータ，カフェイン」ハDiuretin モ稍々瑇性强ン。

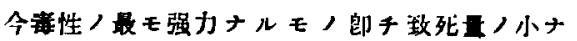

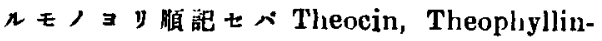
Athylendiamin, 「家息香酸ソーダ,カフェイン」, Diuretin ノ順=シテ，之等 4 物留ノ「マウス」=。 跗スル攻死量八夫々 $1.0 \mathrm{mg}, 2.5 \mathrm{mg}, 4.0 \mathrm{mg}$, $6.0 \mathrm{mg}$, 毒性, 比革八略ボ $6: 2.4: 1.5: 1$ ナ y.

丙. 家鬼二於ケ几实䮲

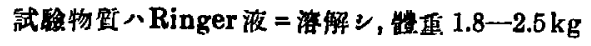

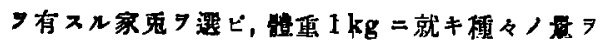

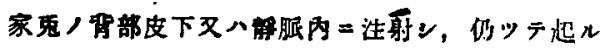

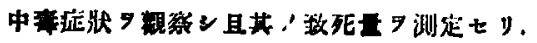

1) Theophyllin-Äthylendiadiamin

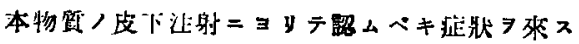

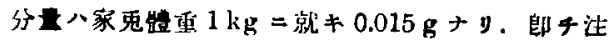

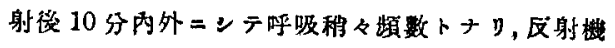
能モ办僅ニ九進スルノ恽てルモ, 30-40分ニシテ 常態 $=$ 復ス. $0.03 \mathrm{~g}=$ 等レバ明カ二叮吸頻数, 反射

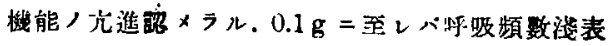

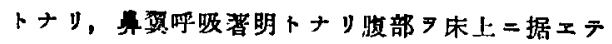

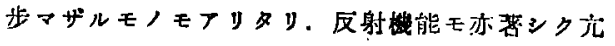

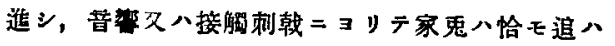
ルモノノ如ク四肢 7 前後二荤動せ七前方二移動七

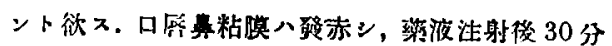
-1 時間後二八多ク八放尿ス. 斯カル狀態八2-3 特間ニンテ漱次消散ン常態二得スルモ，時ニ八前

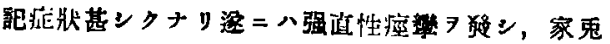

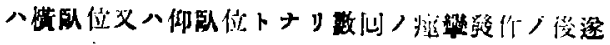


二攃死スn例モアリタリ.0.3 $\mathrm{g}=$ 至レバ上訅症狀

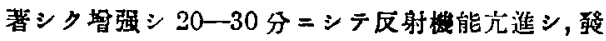

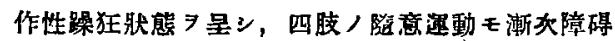

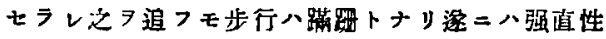
トナリ，横臤位又八仰卧位二倒と，發作性二强通

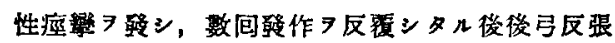

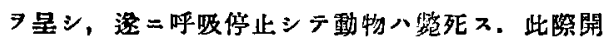
胸ンテ心瞒 $x \gg y$.

2) Theocin (natrioacet.), Diuretin 及ビ 「资 息香酩ソーダ,カフーイン」

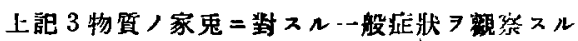

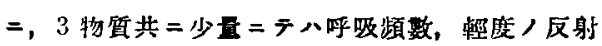

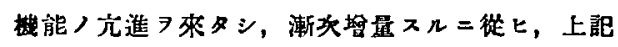

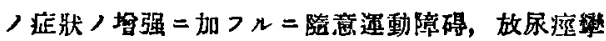

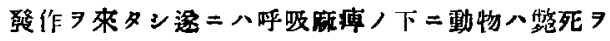

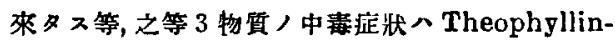
Äthylendiamin ト全ク其ノ軌

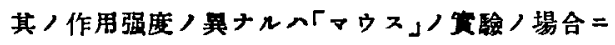

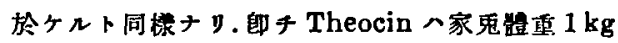
$=$ 就 $+0.01 \mathrm{~g}$ 以上ニテ中毒症爿 $\ni$ 呈ン, $0.1 \mathrm{~g}=$ 造

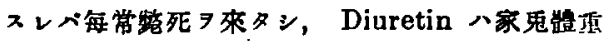
$1 \mathrm{~kg}=$ 就 $\neq 0.07 \mathrm{~g}$ 以上 $=テ$ 始 $\times$ 中菲症狀 7 是

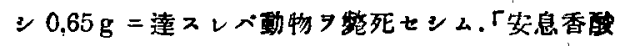
ソータ,カフェイン」八Diuretin =比スレバ

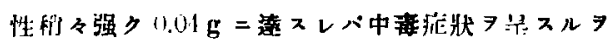

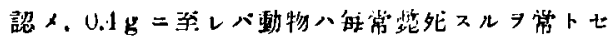
y.

\section{利尿作用比較䚀驗}

Theophyllin-Äthylendiamin

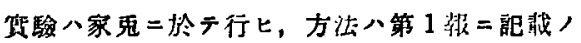

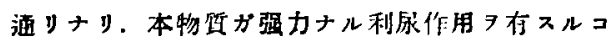

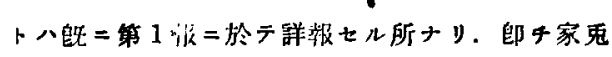
能重 $1 \mathrm{~kg}=$ 就

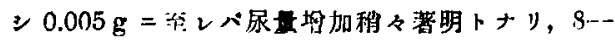

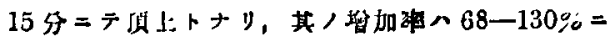

達ス几モ40-50 分ニンテ其／作用全ク消失ス。 $0.01 \mathrm{~g}=$ 至レバ利㲾作用著明ニンテ「腾睄カーウ

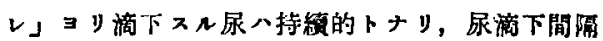

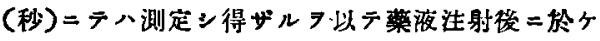

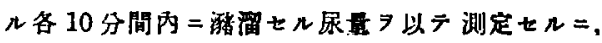

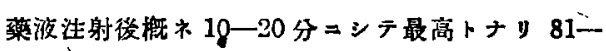

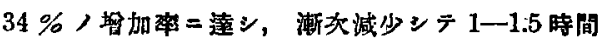

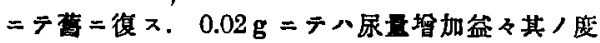

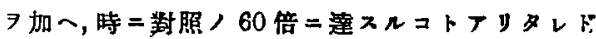

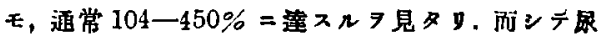

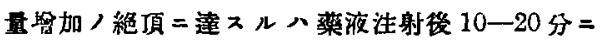
シテ急激二尿量塯加度八減少シ 1.5-2 時間 =シ テ全ク其ノ作用消失 ス。

Theocin

本物算/利用作用强度竝二其/時間的開保入略 末 Theophyllin-Äthylendiamin ト相似》。郎 于家鬼體重 $1 \mathrm{~kg}=$ 就キ $0.002 \mathrm{~g}=ン テ$ 始メテ尿量

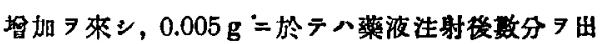
デズンテ利尿作用現ハレ10ー15分ニンテ最大ト

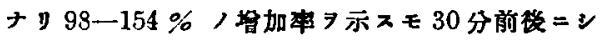

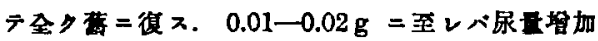

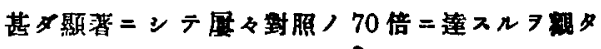

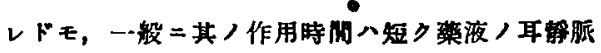

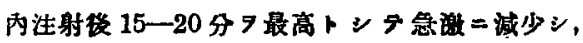
1.5-2 時間

Diuretin

本物丝，家鬼體的 $1 \mathrm{~kg}=$ 就 $\neq 0.002 \mathrm{~g}=$ テ何

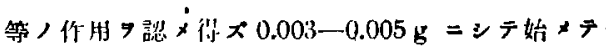

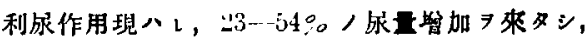

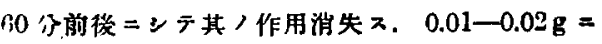

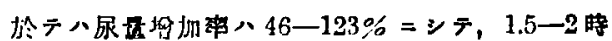

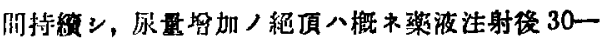
40 分ナルョ数タリ。份隶 0.05-0.1 g =至レベ利

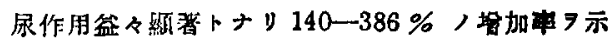
2,1 -2.5 時間持綎 2 .

「安息香酸シーダカフェイン」

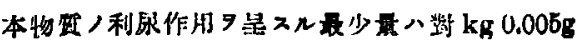




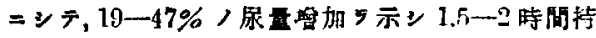

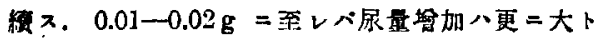
ナリ., 30-164\% =達ン，1-2 時間餘ニシテ其 作用消失ス。份ホ $0.05-0.1 \mathrm{~g}=$ 至ンバ尿量㒄加 益々犬トナリ130-298\% =蓬シ，1.5-2.5 㭙間持

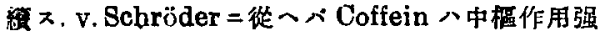

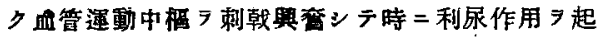

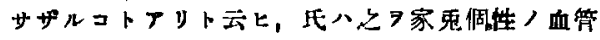

第 3 表

\begin{tabular}{|c|c|c|c|c|}
\hline 品 & $\begin{array}{l}\text { Theophyllin- } \\
\text { Äthylendiamin }\end{array}$ & $\begin{array}{c}\text { Theocin } \\
\text { (natr. acetic.) }\end{array}$ & Diuretin & $\begin{array}{l}\text { Coffeino- } \\
\text { natr. benzoic. }\end{array}$ \\
\hline 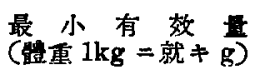 & 0.0002 & 0.002 & 0.004 & 0.005 \\
\hline 作用强度力 & 2.5 & 2.5 & 1.25 & 1.00 \\
\hline
\end{tabular}

郎 $千$ Theophyllin-Äthylendiamin $/$ 利尿作用 フTheocin ノソレト最小有效贵 =於テ略术等シ クDiuretin 及ビ「安息香酸ソーダカフェイン」 八前2者二比ン䅌々分ル ニ於ヶ利尿量作用八Theophyllin-Äthylendia$\min$ 八Theocin =比シ稍々劣ルモ, Diuretin, 「安息香醉ソーダ,カフェイン」ヨリハ迸二優リ， 之等雨者， $2.5-3$ 倍 =䢰 ス，然レドモ利尿作用 持较時間 二於テヘ等 Theophyllin 化合能八 Theobromin, Coffein 複䐴二比ン甚ダ短ク，

'Theophyllin-Äthylendiamin, Theocin 共=利

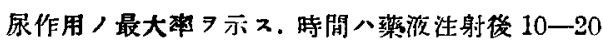
分シンテ其八後激減 7 示ス 7 数儿。

\section{考察端二總括}

Theophyllin-Äthylendiamin ,一般庭彇，蚌

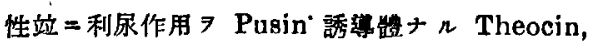
Diuretin, 「安息香酸ソーダカフェイン」ト此校

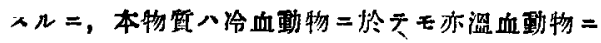
於テモ繁性二於デハDiurttin及ピ安息香酸ソ二

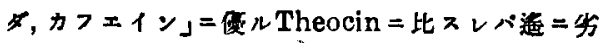

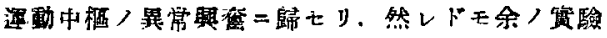
ニ於テハカカル例 7 見ザリキ。恐ラクv.Schröder ノ唱フル如ク斯カル例八家鬼個性ノ然ランムル所 ナルペシ。

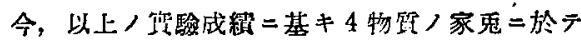
利尿作用 7 永揮スル最小有效量７比校スレバ次表 ノ如シ。

リ，利尿作用 $=$ 於テハ最小有效量ニ於テTheocin ト略ボ同等ナルモ， Diuretin及ビ「安息香酸ンー ダカフェイン」ノ格ボ 1.5一2.5倍ナリ。而シデ中 等量二於ヶル利尿作用八甚ダ强烈ニシテTheocin ，作用卜殆ド相等ンク，Diuretin，2-3倍，「家 息香䣫ソーダカフェイン」ノ3-4借二達スルヨ。 観タリ. Purin 誘莩體利尿濟トシテ Theocin ガ 强烈ナル利沓作用 ガ最モ筑用七ラレタル所以八Theocin ガ毒性甚 ダ强ク Diuretin / 7-8 倍ニ恽シ，且其ノ利尿 作用期問ノ短キニ由ルナルベン. Theophyllin-

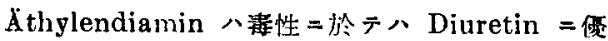
ルモTheocin =比スレバ海二劣り，其ノ利尿作用 强度二於テ八最小有效量站 $=$ 中等量 $/$ 作用强度 $=$ 扲テ Theocin 卜略ボ相等シキョリスレパ，臨片 上ー於テモ利尿劑トンテ推䏺スル＝足ルベシ。只

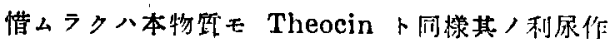
用，持縟ノ短キコトナルモ其ノ毒性弱キ紫 $\Xi リ ス$ レパ反得使用ン得ル 2 


\section{引用書目}

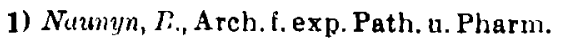
Bd. 3, 1575. 2) Shrö̈der, I., Ebenda. 22, 1857.
3) Sobieranski, Ebenda, Bd. 35, 1995. 4) Lowi,

Ebenda. Bd. 43, 1900.

б) Lehmann, $K . B$., Münch. M. W. 1886, Nr. 23.

Aus dem Pharmakologischen Institut der Medizinischen Fakultät Okayama.

(Vorstand: Prof. Dr. K. Okushima.).

\section{Pharmakologische Studien iiber die Wirknng des Theophyllin- Äthylendianins.}

Von

Dr. Hisafuni Fukuhara.

Eingegangen am, 15. September 1941.

Ein Vergleich der ạllgemeinen Wirkung, Giftigkeit und der diuretischen Wirkung von Theophyllin-Äthylendiamin gegenüber dem Theocin, Diuretin und Coffeinonatrium benzoicum, die Purinderivate sind, ergab folgendes :

1) Die Giftigkeit von Theophyllin-Äthylendiamin ist höher als die von Diuretin und Coffeinonatrium benzoicum, aber geringer als die von Theocin.

2) Die diuretische Wirkung von Theophyllin-äthylendiamin ist in Bezug auf die ninimale wirksame Dose der ron Thencin ebenbürtig, ca 1,5 mal so wirksam als die ron Diuretin und Coffeinonatrium benzoicum, aber bei mittlerer wirksamer Dose ist sie ebenso stark wie die von Theocin, ca 2-3 mal stärker als die von Diuretin, ca 3-4 mal stärker als die von Gofieinonatrium benzoicum.

Wenn sich Diuretin in der Praxis eingebürgert hat, obwohl seine diuretische Wirkung geringer als l,ei Theocin ist, so dürfte der Grund dafür die Tatsache sein, dass die Giftigkeit von Diuretin nicht nur 7-8 mal schwächer ist uls die von Theocin, sondern auch dass die Wirkungszeit von ersterem länger ist als die von letzterem.

Auf Grund des obengenannten Resultates dürfte Theophyllin-Äthylendiamin als ein empfehlenswertes Diureticum zu bezeichnen sein. Es besteht nur insofern eine Lücke, als die Wirkungszeit des Theophyllin-Äthylendiamin als Diuretica kurz ist, wie es bei Theocin der Fall ist, aber durch wiederholte Anwendung karn man diesem Mangel abhelfen, $\mathrm{da}$ die Giftigkeit schwach ist.

(Autorefercat) 